\title{
IMPLEMENTASI CSR PT ASIA FORESTAMA RAYA TERHADAP PEMBERDAYAAN PEREKONOMIAN MASYARAKAT PADA MASA PANDEMI COVID-19
}

\section{HASNATI, SANDRA DEWI, ANDREW SHANDY UTAMA}

Fakultas Hukum Universitas Lancang Kuning

hasnati@unilak.ac.id, sandradewi@unilak.ac.id, andrew.fh.unilak@gmail.com

\begin{abstract}
PT Asia Forestama Raya is a forest product processing factory for the wood industry's raw materials. Based on Article 74 Paragraph (1) of Law Number 40 of 2007 concerning Limited Liability Companies, it is stipulated that companies that carry out their business activities in the natural resources sector and / or fields related to natural resources are required to implement CSR. In Article 10 of Riau Provincial Regulation Number 6 of 2012 concerning Corporate Social Responsibility in Riau Province, it is stated that CSR programs can take the form of community economic empowerment. This research aims to explain the implementation of PT Asia Forestama Raya's CSR on community economic empowerment during the Covid-19 pandemic. The method used in this research is socio-legal research. During the Covid-19 pandemic, the public really expected a real contribution from PT Asia Forestama Raya. PT Asia Forestama Raya's obstacle in implementing community economic empowerment in Limbungan Village is that the financial condition of PT Asia Forestama Raya is currently in an unstable state. Efforts that can be made by the people of Limbungan Village if PT Asia Forestama Raya doesn't carry out a CSR program are to convey their aspirations to Commission IV of DPRD Pekanbaru City. Based on Article 32 of Riau Provincial Regulation Number 6 of 2012 concerning Corporate Social Responsibility in Riau Province, it is stated that if PT Asia Forestama Raya doesn't carry out CSR towards empowering the community's economy, the company can be subject to administrative sanctions by the Pekanbaru City Government.
\end{abstract}

Keyword: CSR; Community Economy; Covid-19

Abstrak: PT Asia Forestama Raya merupakan pabrik pengolahan kayu hasil hutan untuk bahan baku industri kayu. Berdasarkan Pasal 74 Ayat (1) Undang-Undang Nomor 40 Tahun 2007 tentang Perseoran Terbatas diatur bahwa perusahaan yang menjalankan kegiatan usahanya di bidang sumber daya alam dan/atau bidang yang berkaitan dengan sumber daya alam wajib melaksanakan CSR. Pada Pasal 10 Peraturan Daerah Provinsi Riau Nomor 6 Tahun 2012 tentang Tanggung Jawab Sosial Perusahaan di Provinsi Riau disebutkan bahwa program CSR dapat berbentuk pemberdayaan perekonomian masyarakat. Penelitian ini bertujuan untuk menjelaskan implementasi CSR PT Asia Forestama Raya terhadap pemberdayaan perekonomian masyarakat pada masa pandemi Covid-19. Metode yang digunakan dalam penelitian ini adalah penelitian hukum sosiologis. Pada masa pandemi Covid-19, masyarakat sangat mengharapkan adanya kontribusi yang nyata dari PT Asia Forestama Raya. Hambatan PT Asia Forestama Raya dalam melaksanakan pemberdayaan perekonomian masyarakat di Kelurahan Limbungan yaitu kondisi keuangan PT Asia Forestama Raya saat ini sedang dalam keadaan tidak stabil. Upaya yang dapat dilakukan oleh masyarakat Kelurahan Limbungan apabila PT Asia Forestama Raya tidak melaksanakan program CSR yaitu menyampaikan aspirasinya kepada Komisi IV DPRD Kota Pekanbaru. Berdasarkan Pasal 32 Peraturan Daerah Provinsi Riau Nomor E-ISSN: 2657-0300 Lembaga Penelitian dan Penerbitan Hasil Penelitian Ensiklopedia $\quad 25$ P-ISSN: 2657-0319 
6 Tahun 2012 tentang Tanggung Jawab Sosial Perusahaan di Provinsi Riau ditegaskan bahwa apabila PT Asia Forestama Raya tidak melaksanakan CSR terhadap pemberdayaan perekonomian masyarakat, maka perusahaan tersebut dapat dikenakan sanksi administratif oleh Pemko Pekanbaru.

Kata kunci: CSR; Perekonomian Masyarakat; Covid-19

\section{A. Pendahuluan}

Secara umum, prinsip-prinsip yang berlaku dalam kegiatan bisnis sesungguhnya tidak bisa dilepaskan dari kehidupan kita sebagai manusia. Prinsip-prinsip tersebut berkaitan erat dengan sistem nilai yang dianut oleh masyarakat. Adapun prinsip-prinsip dalam etika bisnis antara lain yaitu prinsip kejujuran, prinsip berbuat baik dan tidak berbuat jahat, serta prinsip keadilan (Ridwan Khairandy, 2009). Dilihat dari sisi hukum bisnis, terdapat dua tanggung jawab yang harus diterapkan dalam etika bisnis, yaitu tanggung jawab hukum dan tanggung jawab sosial kepada masyarakat (Andrew Shandy Utama \& Rizana, 2017).

Tanggung jawab sosial pada dasarnya merupakan derivasi dari etika bisnis yang muncul dari adanya interaksi bisnis antarmanusia yang saling melengkapi pemenuhan kebutuhannya sebagai akibat dari kompleksitas kebutuhan manusia yang tidak terbatas (Fahmi, 2015). Etika bisnis dapat menjembatani kepentingan antara perusahaan dan masyarakat, baik masyarakat yang terkena dampak langsung maupun dampak tidak langsung dari kegiatan operasional perusahaan tersebut (Andrew Shandy Utama, 2018). Berdasarkan Pasal 74 Ayat (1) Undang-Undang Nomor 40 Tahun 2007 tentang Perseroan Terbatas diatur bahwa perusahaan yang menjalankan kegiatan usahanya di bidang sumber daya alam dan/atau bidang yang berkaitan dengan sumber daya alam wajib melaksanakan tanggung jawab sosial dan tanggung jawab lingkungan (Andrew Shandy Utama \& Rizana, 2018). Ketentuan ini bertujuan untuk menciptakan hubungan yang seimbang antara perusahaan dan masyarakat (Andrew Shandy Utama, 2018).

Di Indonesia, istilah tanggung jawab sosial perusahaan lebih dikenal dengan sebutan Corporate Social Responsibility (CSR). Lahirnya Peraturan Daerah Provinsi Riau Nomor 6 Tahun 2012 tentang Tanggung Jawab Sosial Perusahaan di Provinsi Riau semakin memperkokoh landasan hukum pelaksanaan CSR bagi perusahaanperusahaan yang beroperasi di wilayah Provinsi Riau (Fahrial, Andrew Shandy Utama \& Sandra Dewi, 2019). Pada Pasal 10 Peraturan Daerah Provinsi Riau Nomor 6 Tahun 2012 tentang Tanggung Jawab Sosial Perusahaan di Provinsi Riau disebutkan bahwa program tanggung jawab sosial perusahaan dapat berbentuk pemberdayaan masyarakat dan/atau kemitraan dan bina lingkungan dan/atau investasi dan/atau sumbangan/donasi, dan/atau promosi. Selanjutnya, pada Pasal 11 peraturan daerah tersebut juga disebutkan bahwa bidang kerja tanggung jawab sosial perusahaan dapat dijalankan pada bidang pendidikan, kesehatan, infrastruktur, olahraga dan seni budaya, sosial dan keagamaan, pelestarian lingkungan hidup, usaha ekonomi kerakyatan, pemberdayaan masyarakat adat, serta bidang kerja lainnya yang secara nyata memberikan dampak peningkatan kualitas masyarakat.

Beberapa bulan terakhir penyebaran wabah Covid-19 di Kota Pekanbaru terus mengalami peningkatan dari waktu ke waktu (Hasnati, Sandra Dewi \& Andrew Shandy Utama, 2020). Kebijakan Pemerintah Kota Pekanbaru menutup pusat-pusat keramaian dan memberlakukan Pembatasan Sosial Berskala Besar (PSBB) hingga Pembatasan Sosial Berskala Mikro (PSBM) di beberapa kecamatan untuk mencegah 
penyebaran wabah Covid-19 sangat berdampak terhadap perekonomian masyarakat, termasuk masyarakat Kelurahan Limbungan. Masyarakat tentu sangat mengharapkan adanya kontribusi yang nyata dari PT Asia Forestama Raya di tengah pandemi Covid19. Dari observasi penelitian yang dilakukan di Kelurahan Limbungan, peneliti memperoleh informasi dari masyarakat bahwa program CSR PT Asia Forestama Raya sangat minim dirasakan oleh masyarakat, terutama dalam hal pemberdayaan perekonomian masyarakat.

CSR merupakan kewajiban yang harus dilaksanakan oleh setiap perusahaan dalam rangka menciptakan hubungan yang baik antara perusahaan dengan masyarakat, terutama masyarakat yang bertempat tinggal di sekitar perusahaan tersebut (Suhendro \& Andrew Shandy Utama, 2019). Berdasarkan latar belakang masalah yang telah dijelaskan di atas, maka permasalahan yang dibahas dalam penelitian ini yaitu bagaimanakah implementasi CSR PT Asia Forestama Raya terhadap pemberdayaan perekonomian masyarakat pada masa pandemi Covid-19?

\section{B. Metodologi Penelitian}

Penelitian hukum adalah suatu kegiatan ilmiah yang didasarkan pada metode, sistematika, dan pemikiran tertentu yang bertujuan untuk mempelajari satu atau beberapa gejala hukum tertentu dengan jalan menganalisanya (Soerjono Soekanto, 2007). Metode yang digunakan dalam penelitian ini adalah penelitian hukum sosiologis. Penelitian hukum sosiologis adalah suatu penelitian yang dilakukan dengan cara menjelaskan pelaksanaan peraturan perundang-undangan terhadap permasalahan yang ada di masyarakat. Sumber data yang digunakan dalam penelitian ini adalah data primer dan data sekunder. Data primer yaitu data yang diperoleh langsung dari hasil observasi, wawancara, dan kuisioner di lokasi penelitian; sedangkan data sekunder yaitu data yang diperoleh dari jurnal-jurnal ilmiah, literatur hukum, dan peraturan perundang-undangan. Teknik pengumpulan data yang digunakan dalam penelitian ini adalah observasi, wawancara, kuisioner, dan studi kepustakaan. Teknik analisis data yang digunakan dalam penelitian ini adalah analisis kualitatif.

\section{Hasil dan Pembahasan}

Pada tahun 2007, terjadi perubahan yang signifikan mengenai CSR di Indonesia setelah disahkannya Undang-Undang Nomor 25 Tahun 2007 tentang Penanaman Modal dan Undang-Undang Nomor 40 Tahun 2007 tentang Perseroan Terbatas (Andrew Shandy Utama, 2018). Disahkannya Undang-Undang Nomor 25 Tahun 2007 tentang Penanaman Modal menjadi dasar hukum pelaksanaan CSR di Indonesia. Ketentuan mengenai CSR diatur secara tegas dalam Pasal 15 Huruf b Undang-Undang Nomor 25 Tahun 2007 tentang Penanaman Modal, yang menegaskan bahwa setiap penanam modal berkewajiban melaksanakan CSR (Andrew Shandy Utama \& Rizana, 2018). Berdasarkan Undang-Undang Nomor 25 Tahun 2007 tentang Penanaman Modal dijelaskan bahwa CSR adalah tanggung jawab yang melekat pada setiap perusahaan penanaman modal untuk tetap menciptakan hubungan yang serasi, seimbang, dan sesuai dengan lingkungan, nilai, norma, dan budaya masyarakat setempat.

Sejalan dengan itu, disahkannya Undang-Undang Nomor 40 Tahun 2007 tentang Perseoran Terbatas melengkapi dasar hukum pelaksanaan CSR di Indonesia. Ketentuan mengenai CSR diatur secara tegas dalam Pasal 74 Ayat (1) Undang-Undang Nomor 40 Tahun 2007 tentang Perseoran Terbatas, yang menegaskan bahwa perusahaan yang menjalankan kegiatan usahanya di bidang sumber daya alam dan/atau E-ISSN: 2657-0300 Lembaga Penelitian dan Penerbitan Hasil Penelitian Ensiklopedia 27 
bidang yang berkaitan dengan sumber daya alam wajib melaksanakan CSR (Andrew Shandy Utama \& Rizana, 2018). Berdasarkan Undang-Undang Nomor 40 Tahun 2007 tentang Perseroan Terbatas dijelaskan bahwa CSR adalah komitmen perusahaan untuk berperan serta dalam pembangunan ekonomi berkelanjutan guna meningkatkan kualitas kehidupan dan lingkungan yang bermanfaat, baik bagi perusahaan sendiri, komunitas setempat, maupun masyarakat pada umumnya.

PT Asia Forestama Raya merupakan pabrik pengolahan kayu hasil hutan untuk bahan baku industri kayu (Suhendro, Andrew Shandy Utama \& Ade Pratiwi Susanty, 2019). PT Asia Forestama Raya mulai beroperasi di Kota Pekanbaru sejak tahun 1986 dengan nama PT Rantau Jaya Sakti, yang berkedudukan di Kelurahan Limbungan. Pada awalnya perusahaan tersebut berdiri di atas lahan kosong berupa hutan di tepi Sungai Siak yang berada di pinggir Kota Pekanbaru. Akan tetapi, seiring dengan perkembangan dan kemajuan Kota Pekanbaru sebagai ibukota Provinsi Riau, saat ini Kelurahan Limbungan telah berubah menjadi daerah padat penduduk. Dari observasi penelitian yang dilakukan di Kelurahan Limbungan, peneliti memperoleh informasi dari masyarakat bahwa program CSR PT Asia Forestama Raya sangat minim dirasakan oleh masyarakat, terutama dalam hal pemberdayaan perekonomian masyarakat. Pada tahun 2017, PT Riau Crumb Rubber Factory juga tidak melaksanakan CSR kepada masyarakat di Kecamatan Rumbai, tetapi tidak ada sanksi yang tegas dari Pemerintah Kota Pekanbaru kepada perusahaan tersebut (Andrew Shandy Utama \& Rizana, 2017).

PT Asia Forestama Raya sebenarnya pernah melaksanakan CSR terhadap pemberdayaan perekonomian masyarakat. Pada tahun 2008, PT Asia Forestama Raya menyediakan sebidang tanah yang terletak di Kelurahan Limbungan untuk pembuatan sebuah pasar tradisional yang dikelola oleh masyarakat dan pasar tersebut masih ada sampai sekarang (Andrew Shandy Utama, Rizana, \& Tri Anggara Putra, 2019).

Program Integrated Farming System dan Program UMKM sebagai salah satu CSR dari PT Riau Andalan Pulp and Paper berdampak positif terhadap peningkatan perekonomian masyarakat Kabupaten Pelalawan (Andrew Shandy Utama, 2018). Keberhasilan suatu daerah dalam meningkatkan kesejahteraan masyarakatnya dapat terwujud apabila seluruh komponen masyarakat ikut dilibatkan, termasuk partisipasi yang nyata dari perusahaan yang beroperasi di daerah tersebut (Fahrial, Rini Fatriani \& Andrew Shandy Utama, 2020). Dalam beberapa bulan terakhir penyebaran wabah Covid-19 di Kota Pekanbaru terus mengalami peningkatan dari waktu ke waktu. Kebijakan Pemerintah Kota Pekanbaru menutup pusat-pusat keramaian dan memberlakukan Pembatasan Sosial Berskala Besar (PSBB) hingga Pembatasan Sosial Berskala Mikro (PSBM) di beberapa kecamatan untuk mencegah penyebaran wabah Covid-19 sangat berdampak terhadap perekonomian masyarakat, termasuk masyarakat Kelurahan Limbungan. Masyarakat tentu sangat mengharapkan adanya kontribusi yang nyata dari PT Asia Forestama Raya di tengah pandemi Covid-19.

Hambatan dalam pelaksanaan CSR PT Asia Forestama Raya terhadap pemberdayaan perekonomian masyarakat di Kelurahan Limbungan dari sisi perusahaan yaitu kondisi keuangan PT Asia Forestama Raya saat ini sedang dalam keadaan tidak stabil sehingga sudah tiga tahun tidak ada melaksanakan program pemberdayaan perekonomian masyarakat. Sedangkan, hambatan dalam pelaksanaan CSR PT Asia Forestama Raya terhadap pemberdayaan perekonomian masyarakat di Kelurahan Limbungan dari sisi masyarakat yaitu minimnya pengetahuan masyarakat 
mengenai Peraturan Daerah Provinsi Riau Nomor 6 Tahun 2012 tentang Tanggung Jawab Sosial Perusahaan di Provinsi Riau.

Program CSR sebenarnya bukan hanya bermanfaat bagi masyarakat, melainkan juga bermanfaat untuk membentuk citra perusahaan apabila dikemas dengan publikasi yang tepat (Hasnati \& Andrew Shandy Utama, 2020). Dalam rangka menjaga efektivitas pelaksanaan Peraturan Daerah Provinsi Riau Nomor 6 Tahun 2012 tentang Tanggung Jawab Sosial Perusahaan di Provinsi Riau, maka dibutuhkan adanya pengawasan yang intensif dari pemerintah (Andrew Shandy Utama, 2020). Upaya yang dapat dilakukan oleh masyarakat Kelurahan Limbungan apabila PT Asia Forestama Raya tidak melaksanakan program pemberdayaan perekonomian masyarakat yaitu menyampaikan aspirasinya kepada Komisi IV DPRD Kota Pekanbaru agar perusahaan tersebut direkomendasikan menerima sanksi yang tegas dari Pemerintah Kota Pekanbaru.

Berdasarkan Pasal 32 Peraturan Daerah Provinsi Riau Nomor 6 Tahun 2012 tentang Tanggung Jawab Sosial Perusahaan di Provinsi Riau ditegaskan bahwa apabila PT Asia Forestama Raya tidak melaksanakan CSR terhadap pemberdayaan perekonomian masyarakat, maka perusahaan tersebut dapat dikenakan sanksi administratif berupa peringatan tertulis dari Pemerintah Kota Pekanbaru serta pembatasan kegiatan usaha perusahaan, pembekuan izin usaha perusahaan, hingga pencabutan izin usaha perusahaan tersebut.

\section{Penutup}

PT Asia Forestama Raya merupakan pabrik pengolahan kayu hasil hutan untuk bahan baku industri kayu. Berdasarkan Pasal 74 Ayat (1) Undang-Undang Nomor 40 Tahun 2007 tentang Perseoran Terbatas diatur bahwa perusahaan yang menjalankan kegiatan usahanya di bidang sumber daya alam dan/atau bidang yang berkaitan dengan sumber daya alam wajib melaksanakan CSR. Pada Pasal 10 Peraturan Daerah Provinsi Riau Nomor 6 Tahun 2012 tentang Tanggung Jawab Sosial Perusahaan di Provinsi Riau disebutkan bahwa program CSR dapat berbentuk pemberdayaan perekonomian masyarakat. Pada masa pandemi Covid-19, masyarakat sangat mengharapkan adanya kontribusi yang nyata dari PT Asia Forestama Raya. Hambatan PT Asia Forestama Raya dalam melaksanakan pemberdayaan perekonomian masyarakat di Kelurahan Limbungan yaitu kondisi keuangan PT Asia Forestama Raya saat ini sedang dalam keadaan tidak stabil. Upaya yang dapat dilakukan oleh masyarakat Kelurahan Limbungan apabila PT Asia Forestama Raya tidak melaksanakan program CSR yaitu menyampaikan aspirasinya kepada Komisi IV DPRD Kota Pekanbaru. Berdasarkan Pasal 32 Peraturan Daerah Provinsi Riau Nomor 6 Tahun 2012 tentang Tanggung Jawab Sosial Perusahaan di Provinsi Riau ditegaskan bahwa apabila PT Asia Forestama Raya tidak melaksanakan CSR terhadap pemberdayaan perekonomian masyarakat, maka perusahaan tersebut dapat dikenakan sanksi administratif oleh Pemerintah Kota Pekanbaru.

\section{Daftar Pustaka}

Andrew Shandy Utama. (2018). Implementasi Corporate Social Responsibility PT Riau Andalan Pulp \& Paper terhadap Masyarakat di Kabupaten Pelalawan. Selat, 5 (2), 123-133.

Andrew Shandy Utama. (2018). The Implementation of Corporate Social Responsibility (CSR) PT Riau Crumb Rubber Factory to the Community of Sri Meranti Village in Pekanbaru. International Conference Icon-ITSD, 175, 1-6. 
Andrew Shandy Utama. (2018). Pelaksanaan Tanggung Jawab Sosial dan Lingkungan Perusahaan Berdasarkan Undang-Undang Nomor 40 Tahun 2007 untuk Meningkatkan Kesejahteraan Masyarakat Kecamatan Rumbai Pesisir Kota Pekanbaru. Cendekia Hukum, IV (1), 26-36.

Andrew Shandy Utama. (2018). Problematika dalam Pelaksanaan Tanggung Jawab Sosial Perusahaan Kehutanan dan Perkebunan di Kabupaten Pelalawan Provinsi Riau. Supremasi Hukum, 1 (2), 67-80.

Andrew Shandy Utama. (2020). Pemanfaatan Program CSR Perusahaan untuk Pemberdayaan Perekonomian Masyarakat Kabupaten Pelalawan di Masa Pandemi Covid-19. Seminar Nasional Pemberdayaan Masyarakat, 2, 77-83.

Andrew Shandy Utama \& Rizana. (2017). Implementasi Corporate Social Responsibility PT Riau Crumb Rubber Factory terhadap Masyarakat Kelurahan Sri Meranti Kota Pekanbaru. Novelty, 8 (2), 173-186.

Andrew Shandy Utama \& Rizana. (2018). Penegakan Hukum terhadap Pelaksanaan Tanggung Jawab Sosial Perusahaan di Kecamatan Rumbai Pekanbaru. Equitable, 3 (1), 1-11.

Andrew Shandy Utama \& Rizana. (2018). Upaya Hukum Masyarakat Kecamatan Rumbai Pekanbaru dalam Pemenuhan Hak Masyarakat Melalui Program Corporate Social Responsibility (CSR). Melayunesia Law, 2 (1), 79-93.

Andrew Shandy Utama \& Rizana. (2018). Pelaksanaan Corporate Social Responsibility dalam Rangka Optimalisasi Pelestarian Lingkungan. Litigasi, 19 (2), 127-147.

Andrew Shandy Utama, Rizana \& Tri Anggara Putra. (2019). Tanggung Jawab Sosial Perusahaan PT Asia Forestama Raya di Kota Pekanbaru dan Penegakan Hukumnya. Pagaruyuang Law, 2 (2), 148-162.

Fahmi. 2015. Pergeseran Tanggung Jawab Sosial Perseroan; Dari Tanggung Jawab Moral ke Tanggung Jawab Hukum. Yogyakarta: FH UII Press.

Fahrial, Andrew Shandy Utama \& Sandra Dewi. (2019). Pemanfaatan Corporate Social Responsibility (CSR) terhadap Pembangunan Perekonomian Desa. Wawasan Yuridika, 3 (2), 259-272.

Fahrial, Rini Fatriani \& Andrew Shandy Utama. (2020). Utilization of Corporate Social and Environmental Responsibility to Improve Community Economy in Pekanbaru City. Proceeding of International Conference ICE-Tech, 469, 1-5.

Hasnati \& Andrew Shandy Utama. (2020). Implementation of Corporate Social Responsibility (CSR) by Forestry and Plantation Companies in Pelalawan Regency, Riau Province, Indonesia. Law and Political Sciences, 25 (4), 309-332. Hasnati, Sandra Dewi \& Andrew Shandy Utama. (2020). Program CSR Perusahaan; Alternatif Pemberdayaan Ekonomi Masyarakat Desa. Comsep, 1 (1), 25-31.

Ridwan Khairandy. 2009. Perseroan Terbatas: Doktrin, Peraturan Perundangundangan, dan Yurisprudensi. Yogyakarta: Kreasi Total Media.

Nelfira, Nelfira, Hariyadi Hariyadi, and Muhammad Ridho. "Aplikasi Pemasaran dan Penjualan Karangan Bunga Berbasis Website Menggunakan Metode Fifo pada CV. Dikrez Florist." Rang Teknik Journal 4.1 (2021): 109-116.

Soerjono Soekanto. 2007. Pengantar Penelitian Hukum. Jakarta: UI Press.

Suhendro, Andrew Shandy Utama \& Ade Pratiwi Susanty. (2019). Pelaksanaan CSR PT Asia Forestama Raya terhadap Peningkatan Perekonomian Masyarakat 
Berdasarkan Peraturan Daerah Provinsi Riau Nomor 6 Tahun 2012. Ensiklopedia Social Review, 1 (2), 140-144.

Suhendro \& Andrew Shandy Utama. (2019). Implementation of Corporate Social Responsibility by PT Asia Forestama Raya in Rumbai Pesisir District of Pekanbaru City Based on Regional Regulation of Riau Province 6 of 2012. Agricultural and Socio-Economic Sciences, 9 (93), 274-284. 